The Biohistorical Institute of the University of Utrecht

Tre new Biohistorical Institute of the University of Utrecht was formally dedicated on May 30. Among the speakers were Prof. J. Lanjouw (director of the Utrecht Institute for Systematic Botany), who made the original plans for the Institute, and Prof. G. A. Lindeboom (Free University of Amsterdam), who spoke on the importance of the humanistic aspects of biology and early medicine in general. Prof. F. Verdoorn, the Institute's director, outlined the concept of biohistory, that is, all areas where the pure and applied life sciences (including early medicine), on one hand, and cultural history, literary and art history, and sundry other branches of the humanities, on the other, overlap. He also described how an effort is being made to develop the Utrecht Biohistorical Institute simultaneously as a research, as an educational, as a documentation and (in conjunction with the International Biohistorical Bureau) as an international institution. In the annals of the University of Utrecht, the Biohistorical Institute is unique by being housed in one of the oldest University buildings (which served for more than two centuries as the official residence of the director of the Hortus Academicus), while the contents (the former Chronica Botanica Library and Archives) were chiefly built up in the United States.

As to the organization of the Biohistorical Institute, there are three divisions of a primary nature, each constituting a 'triple unity' and consisting of $(a)$ books, (b) extensive card indexes of the relevant world literature, and $(c)$ supplementary archivalia (such as engravings, autographs, manuscripts, portraits), the historical and bibliographical, the biographical, and the topographical division. Other units are the literary and art historical division, the reading and periodicals room, etc. In connexion with the dedication of the Utrecht Biohistorical Institute, a number of selective exhibits from the Institute's own holdings were organized, including: (1) garden history and landscape architecture in the past and present; (2) Nature prints; (3) works by and about Carolus Linnaeus, mainly of a genoral biological and medical interest; (4) literature and art in biology and early medicine; (5) works edited by Fr. and J. G. Verdoorn (1935-62); (6) recent acquisitions of the Institute's Library; (7) Leeuwenhoeckiana (a survey of the work of the Leeuwenhoek Commission of the Royal Netherlands Academy of Sciences, which has its headquarters at the Utrecht Biohistorical Institute).

\section{The British National Committee on Surface Active} Agents

THe British National Committee on Surface Active Agents has recently been inaugurated. Membership is open to all bona fide manufacturers of surface active agents in the United Kingdom. The Committee has been formed primarily to foster British interests in the field of surface activity on an international basis. Its aims and objects have been defined as: $(a)$ to seek membership of the Comité International de la Détergence; (b) to consider all questions of a technical character relating to the work of the Comité International de la Détergence, its technical Commissions and International Standards Organization Committees on Surface Activity; (c) to maintain liaison with organizations and individuals in the United Kingdom having interests in the field of surface activity; $(d)$ to co-ordinate participation by the United Kingdom in International Congresses on
Detergency. The seventeen founder members include all the major manufacturers of surface active agents in the United Kingdom. The officers are: Mr. R. C. Tarring, Shell Chemical Co., Ltd. (president); Dr. A. F. Kertess, Associated Chemical Companies, Ltd. (treasurer); Mr. H. W. Vallender (secretary-general). Further information concerning membership, etc., can bo obtained from the Secretary-General at 86 Strand, London, W.C.2.

\section{John Alexander Reina Newlands}

Dr. F. W. Grobs, of the Royal Institute of Chemistry, has recently provided the editor of Nature with the following information: "John Alexander Reina Newlands, propounder of the 'Law of Octaves', died on July 29, 1898, aged sixty (according to 'W. S.', $J$. Soc. Chem. Indust., $743 ; 1898)$ or sixty-ono ('W. A. T.', Nature, 58, 395; 1898). The year of his birth has thus been stated by some as 1838 and by others as 1837. Comprehensive registration of births began in the summer of 1837 , and a search at Somerset House has revealed the existence of a birth certificate. It transpires that Newlands was born at the family address, 19 West Square, Southwark, on November 26,1837 . The birth was registered on December 26 (Bank holidays were introduced by the Act of 1871). His father, William Newlands, was a Presbyterian minister and his mother was formerly Mary Sarah Reina".

\section{Radiation and Health}

In October 1960, the International Atomic Energy Agency and the World Health Organization sponsored a scientific meeting on the diagnosis and treatment of acute radiation injury (Diagnosis and Treatment of Acute Radiation Injury. Pp. 425. Geneva: World Health Organization, 1961. £2). The proceedings were reviewed together with other recent developments in radiation medicine in a special number of the WHO Chronicle published in December 1961, and have recently been reprinted as a brochure (Radiation and Health. Pp. 44. Geneva: World Health Organization, 1962 . 1s. $9 d$.). In addition to three general sections on radiation protection, there are short reviews on health hazards from nuclearpowered merchant ships, accidental radiation injury, management of radiation casualties, therapeutic uses of radiation injury, and statisties in genetic and radiation studies.

\section{Radioactivity in Diet}

THE seventh report of the Agricultural Research Council's Radiobiological Laboratory (H.M.S.O., $A R C L \quad 7$ ) records measurements carried out between December 1961 and April 1962. The resumption of nuclear weapons trials in September 1961 lends particular interest to this interim report. Iodine-131 reached a maximaum concentration in milk about the end of Oetober 1961 (see ARCL 6) and thereafter fell rapidly to levels below the limits of detection by the beginning of 1962 . The country-wide average in milk over the period of 32 weeks following the resumption of nuclear weapon trials was 17 per cent of that which would give rise to the annual average of 130 picocuries per litre which the Medical Research Council has stated would not cause the acceptable radiation dose to be exceeded for any age group of the population. The strontium-90 levels in milk rose by about 20 per cent between October and December 1961 as compared with the corresponding levels the previous year although the country-wide figure cal- 